\title{
Role of platelet activating factor on the fibrinolytic activation in the pathogenesis of gastric mucosal damage induced by endothelin-1
}

\author{
I Kurose, S Miura, D Fukumura, H Tashiro, H Imaeda, H Shiozaki, M Suematsu, H Nagata, \\ E Sekizuka, M Tsuchiya
}

\begin{abstract}
We have examined the hypothesis that the release of tissue type plasminogen activator may play a prominent role in endothelin induced gastric mucosal injury. We determined tissue type plasminogen activator activity in the regional blood sample and the concentration of platelet activating factor in the gastric mucosa after the administration of endothelin-1 in a range of $50-500 \mathrm{pmol} /$ $\mathrm{kg}$ into the left gastric artery of male Wistar rats. Endothelin-1 increased the tissue type plasminogen activator release and platelet activating factor formation, and induced subsequent gastric mucosal haemorrhagic change in a dose dependent manner. In addition CV6209 , a selective platelet activating factor blocker, attenuated the activation of regional tissue type plasminogen activator and the development of mucosal damage induced by endothelin-1. The results of this study showed that tissue type plasminogen activator activation may play an important role in the pathogenesis of endothelin induced mucosal injury of rat stomach, and suggest that the platelet activating factor may be involved in the process of regional fibrinolytic activation induced by endothelin-1.
\end{abstract}

Microcirculatory disturbances of the stomach are thought to be one of the factors contributing to the development of gastric mucosal damages. A previous study has shown that mucosal tissue type plasminogen activator, when released from endothelial cells by platelet activating factor, plays an important role in the process of gastric ulcer formation by inducing macromolecular permeable change in the rat experimental model.' We have also reported that endothelin-1 is synthesised in the endothelial cells of submucosal arterioles in the early phase of the development of gastric mucosal injury in the same experimental model. ${ }^{2}$ In addition, it was recently reported that endothelin can increase the fibrinolytic activity in vivo and in vitro. ${ }^{3}$ These results give rise to the hypothesis that endothelin might increase the tissue type plasminogen activator activity accompanying the gastric mucosal injury. No detailed studies have been carried out, however, on the involvement of endothelin-1 in the fibrinolytic activation during the pathogenesis of gastric mucosal haemorrhagic lesions.

The aim of this study is to elucidate the effect of endothelin-1 on the tissue type plasminogen activator activation followed by mucosal damage in the rat stomach. In addition we have also investigated the involvement of platelet activating factor in the endothelin induced fibrinolytic activation.

\section{Methods}

ANIMALS

Male Wistar rats $(250 \mathrm{~g}$ ) were used as the experimental animal. These animals were deprived of food for 24 hours before the start of experiment, but permitted of free access to drinking water. Under anaesthesia with pentobarbital sodium, a median incision was made in the abdomen and the gastric pylorus was ligated with silk thread. Endothelin induced gastric mucosal damage was carried out as described below. Two millilitres $0 \cdot 1 \mathrm{~N} \mathrm{HCl}$ was instilled into the gastric cavity through the forestomach with 27 gauge needle. Using 30 gauge needle, $100 \mu \mathrm{l}$ Krebs-Ringer solution containing endothelin-1 (Peptide Laboratory, Osaka, Japan) was injected as a bolus into the left gastric artery in a range of 50-500 pmol/kg. As the control group, $100 \mu \mathrm{mol}$ of Krebs-Ringer solution alone was injected into the left gastric artery. At various periods after the injection of endothelin-1, the stomach was removed and opened along the greater curvature. The length and width of each lesion were measured, and the area of macroscopic lesion was determined. The total area of lesions was calculated as the sum of areas of individual lesion.

To determine the tissue type plasminogen activator activity in the regional blood of rat stomach, a $200 \mu \mathrm{l}$ blood sample was collected from the gastric vein before and after the injection of endothelin-1 which was then transferred to a glass container containing $10 \mu \mathrm{l}$ disodium citrate dihydrate $(0 \cdot 13 \mathrm{M})$. The container was immediately placed in an ice bath. Plasma was separated by centrifugation for five minutes at $2000 \mathrm{rpm}\left(4^{\circ} \mathrm{C}\right)$, frozen and stored at $-70^{\circ} \mathrm{C}$ in small aliquots. Tissue type plasminogen activator activity in plasma was assayed by the specific chromogenic substrate assay, which 
Time course changes of mucosal lesions and tissue-type plasminogen activator ( $t-P A)$ activity in regional plasma of stomach induced by endothelin-1 $500 \mathrm{pmol} / \mathrm{kg}$

\begin{tabular}{|c|c|c|c|c|}
\hline \multirow{2}{*}{$\begin{array}{l}\text { Group } \\
\text { Before injection (minutes) } \\
\text { Endothelin-1 (5) } \\
\text { Endothelin-1 (10) } \\
\text { Endothelin-1 (15) } \\
\text { Endothelin-1 (30) } \\
\text { Control (30) }\end{array}$} & \multicolumn{2}{|c|}{ Area of mucosal lesion $\left(\mathrm{mm}^{2}\right)$} & \multicolumn{2}{|c|}{$t-P A \operatorname{activity}(I U / m l)$} \\
\hline & $\begin{array}{l}0 \\
0 \cdot 1(0.4) \\
4 \cdot 4(3.9) \\
9 \cdot 8(4 \cdot 6) \\
34 \cdot 5(10.5) \\
1 \cdot 0(0.9)\end{array}$ & $\begin{array}{l}\text { NS } \\
\mathrm{p}<0.001 \\
\mathrm{p}<0.05 \\
\mathrm{p}<0.001 \\
\mathrm{p}<0.001\end{array}$ & $\begin{array}{l}2.5(1.5) \\
2.6(1 \cdot 3) \\
5.0(2 \cdot 2) \\
7.9(2.9) \\
8 \cdot 1(3.1) \\
2.8(1.1)\end{array}$ & $\begin{array}{l}\text { NS } \\
\mathrm{p}<0.01 \\
\mathrm{p}<0.01 \\
\mathrm{NS} \\
\mathrm{p}<0.00\end{array}$ \\
\hline
\end{tabular}

Data are expressed as mean $(\mathrm{SD})$ from seven experiments.

was a modification of the method described by Rånby et al. ${ }^{+}$Briefly, the activity of tissue type plasminogen activator can be measured by adding Glu-plasminogen, chromogenic plasmin substrate and fibrin (purchased from Biopool Co, Umeå, Sweden) at neutral $\mathrm{pH}$. In the presence of fibrin, tissue type plasminogen activator converts plasminogen to plasmin, which subsequently cleaves the chromogenic substrate. The amount of colour developed during a fixed time is proportional to the tissue type plasminogen activator activity in the sample.

The level of platelet activating factor in the rat gastric mucosa was determined after the administration of endothelin-1 using a radioimmunoassay method. Rats were decapitated and the stomach were removed, opened along the greater curvature. The mucosal surface was rinsed with ice cold isotonic saline solution. For separation of the mucosal layer of the grandular stomach, the tissues were mounted on a glass slide, covered with another glass slide, and immersed in hexane at $-60^{\circ} \mathrm{C}$. The mucosal and muscular tissue layers were then separated by quickly pulling the two slides apart. Total lipids of mucosal homogenate of rat antrum were extracted by the method of Bligh and Dyer ${ }^{5}$ at $4^{\circ} \mathrm{C}$ in the presence of $50 \mathrm{mM}$ glycine $\mathrm{HCl}$ buffer

Figure 1: Area of gastric mucosal lesion, tissue type plasminogen activator $(t-P A)$ activity and platelet activating factor (PAF) content after the administration of endothelin-1. The area of macroscopic mucosal lesion and the $t-P A$ activity in the regional blood sample from rat gastric vein were determined at 30 minutes after the intraarterial injection of endothelin-1 in the range of 50-500 pmol/kg. In this range endothelin-1 caused the mucosal haemorrhagic lesion in rat stomach and $t-P A$ activation in a dose dependent manner ( $A$ and $B$ ). The PAF content of gastric mucosa was measured at five minutes after the administration of endothelin-1 in the same range. Endothelin-1 in doses greater than $250 \mathrm{pmol} / \mathrm{kg}$ significantly increased the significantly increased the
$P A F$ content as compared with the control value $(C)$ Data are expressed as mean (SD) from seven experiments $(A$ and $B)$ or four experiments $(C) .{ }^{\star} p<0.05$ $\star \star p<0.01$ and $\star \star \star p<0.001$ as compared with the control value.
$(\mathrm{pH} 2 \cdot 8)$ in a one phase system to inactivate platelet activating factor acetylhydolase. ${ }^{6}$ The chloroform layer, which contains the purified lipid extract, was isolated and used to determine the platelet activating factor concentration, using the platelet activating factor $\left[{ }^{3} \mathrm{H}\right]$ scintillation proximity assay system purchased from Amersham International plc (UK). The assay system is based on the competition between unlabelled platelet activating factor and a fixed quantity of $\left[{ }^{3} \mathrm{H}\right]$ labelled platelet activating factor for a limited number of binding sites on a platelet activating factor specific antibody. The platelet activating factor concentration of mucosa from rat antrum was expressed as $\mathrm{pmol} / \mathrm{g}$ frozen tissue.

To assess the involvement of platelet activating factor in the endothelin induced tissue type plasminogen activator activation in gastric mucosa, CV-6209 (a gift from Takeda Pharm Co, Osaka, Japan), a selective platelet activating factor blocker, was intravenously administered at a dose of $0.001-0.1 \mathrm{mg} / \mathrm{kg}$ five minutes before the injection of endothelin-1.

The statistical significance of the difference between the mean value of groups was tested by Student's $t$ test for unpaired values.

\section{Results}

As shown in the Table, the area of mucosal lesions was time dependently increased after the injection of endothelin-1 (500 pmol/kg). Red spots were sporadically seen on the mucosa at 10 minutes after the injection of endothelin-1. At 30 minutes after the injection, multiple haemorrhagic erosions and linear ulcers were observed grossly. The application of $0 \cdot 1 \mathrm{~N} \mathrm{HCl}$ caused no remarkable change in the gastric mucosa at 30 minutes (Table). Figure 1A shows the area of lesion which was calculated at 30 minutes after the injection of endothelin-1 in a range of 50-500 $\mathrm{pmol} / \mathrm{kg}$. Endothelin-1 in this range induced mucosal haemorrhagic changes in a dose dependent manner.

Before the administration of endothelin-1 ( 500 $\mathrm{pmol} / \mathrm{kg}$ ), the activity of tissue type plasminogen activator in regional blood sample of stomach was $2.5(1 \cdot 5) \mathrm{IU} / \mathrm{ml}$. The activity of tissue type plasminogen activator was significantly raised 10 minutes after the injection of endothelin-1 and gradually increased to $8 \cdot 1(3 \cdot 1) \mathrm{IU} / \mathrm{ml}$ at 30 minutes (mean (SD) $\mathrm{n}=7, \mathrm{p}<0.001$ ). No significant increase in tissue type plasminogen activator activity was induced, however, by the administration of $0 \cdot 1 \mathrm{~N} \mathrm{HCl}$ alone into the gastric cavity at 30 minutes aftr the injection (Table). It was also shown that the local administration of endothelin-1 elicited tissue type plasminogen activator activity in a dose dependent manner at 30 minutes (Fig 1B). To see whether the area of mucosal lesion is correlated to the tissue type plasminogen activator activity, these two parameters were plotted as shown in Figure 2. The individual tissue type plasminogen activator activity and damaged area was determined 30 minutes after the administration of endothelin-1 in the various concentrations $(50,100,250$, and $500 \mathrm{pmol} / \mathrm{kg}$ ), each of which consisted of seven experiments. It was clearly shown that tissue 


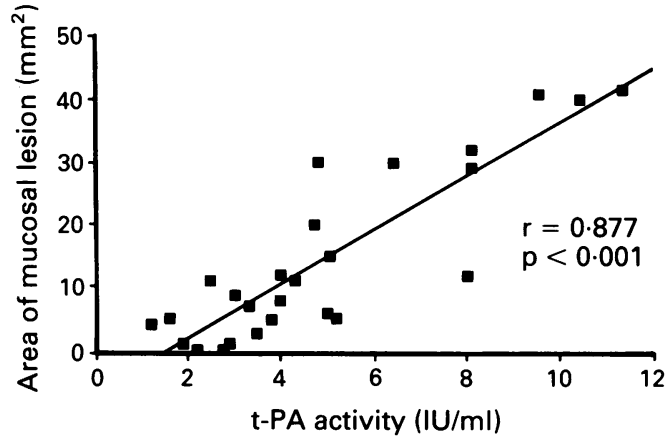

Figure 2: Relationship between gastric mucosal lesion and tissue type plasminogen activator ( $t-P A)$ activity induced by endothelin-1. The area of mucosal lesion and the t-PA activity were plotted (vertical: area of mucosal lesion, horizontal: $t-P A$ activity). The individual $t-P A$ activity and damaged area were determined at 30 minutes after the injection of endothelin-1 50, 100, 250, and 500 pmoll kg, each of which consisted of seven experiments. $t-P A$ activity in the regional blood sample was significantly proportional to the area of lesion induced by endothelin- $1(r=0.877, p<0.001)$.

type plasminogen activator activity was significantly correlated with the mucosal lesion $(\mathrm{r}=0.877, \mathrm{p}<0.001)$.

To investigate one of the mechanisms by which the tissue type plasminogen activator activity in regional blood increased, the platelet activating factor content of the gastric mucosa was measured before, five, and 30 minutes after the administration of endothelin-1 (500 $\mathrm{pmol} / \mathrm{kg}$ ). In the gastric mucosa before the endothelin-1 injection, platelet activating factor content was $28.0(7 \cdot 1) \mathrm{pmol} / \mathrm{g}$ frozen tissue (mean (SD) $\mathrm{n}=4$ ). Platelet activating factor content increased five minutes after the administration of endothelin-1 (64.0 (11.4) $n=4$, $\mathrm{p}<0.01)$ and decreased to $44.5(11)$ at 30 minutes $(\mathrm{p}<0.05)$ (Fig 3). Endothelin-1 in doses greater than $250 \mathrm{pmol} / \mathrm{kg}$ increased the platelet activating factor content at five minutes as compared with the control value $(27 \cdot 0(6 \cdot 1))$ (Fig $1 C)$.

The effects of the pretreatment with CV-6209 $(0.001,0.01$, or $0.1 \mathrm{mg} / \mathrm{kg})$, a selective platelet activating factor blocker, on both the mucosal injury and the tissue type plasminogen activator activation induced by endothelin- $1500 \mathrm{pmol} / \mathrm{kg}$ were tested. Figure 4A shows the effect of CV-

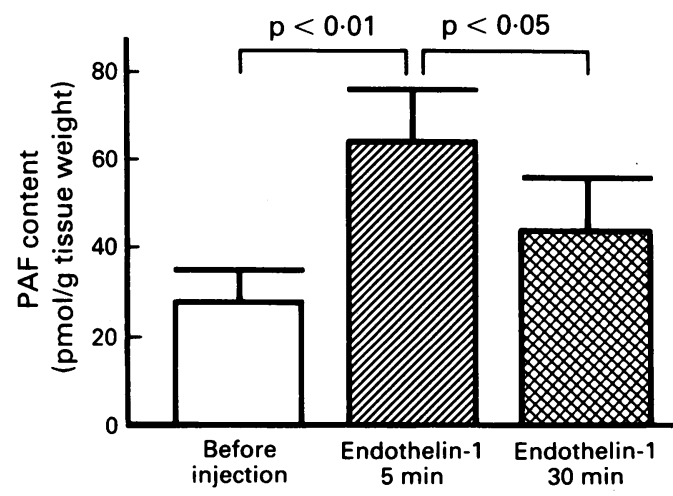

Figure 3: Time course change of platelet activating factor $(P A F)$ content in the rat gastric mucosa. The PAF content before, five and 30 minutes after the administration of endothelin-1 was determined by the radioimmunoassay. The $P A F$ content showed a significant rise at five minutes and decreased to the pretreatment level at 30 minutes after the injection. Data were obtained from four experiments and expressed as mean (SD) (pmol/g frozen tissue).
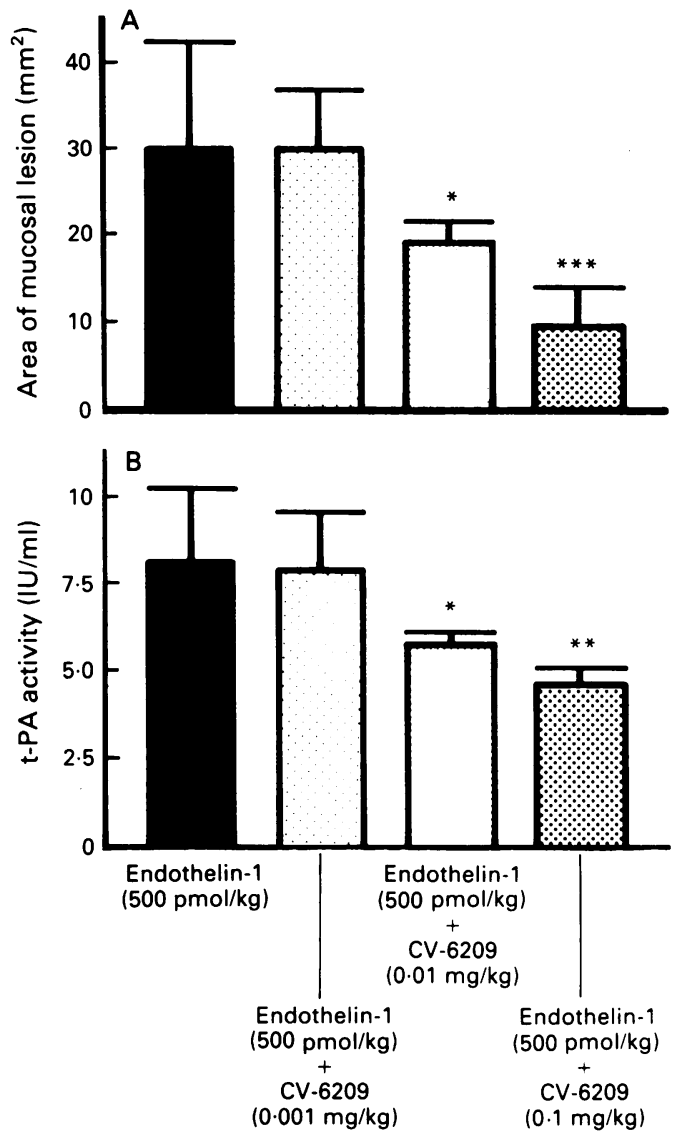

Figure 4: Effects of CV-6209 on the gastric mucosal lesion and the tissue type plasminogen activator $(t-P A)$ activation induced by endothelin-1. The pretreatment of $C V-6209$ in the doses more than $0.01 \mathrm{mg} / \mathrm{kg}$ significantly attenuated the mucosal damage and increased $t-P A$ activity induced by endothelin-1 at 30 minutes. Data are expressed as mean (SD) from seven experiments. ${ }^{\star} p<0.05,{ }^{\star}{ } p<0.01$ and $\star \star \star p<0.001$ as compared with the value of endothelin-1 500 pmollkg.

6209 on the endothelin induced gastric mucosal injury. The pretreatment of CV-6209 attenuated the mucosal damage at 30 minutes in a dose dependent manner. At the same time, the tissue type plasminogen activator activity induced by endothelin-1 was also attenuated by CV-6209 more than $0.01 \mathrm{mg} / \mathrm{kg}$ (Fig 4B). These results suggest the involvement of platelet activating factor in the endothelin induced fibrinolytic activation and subsequently developed mucosal haemorrhagic lesion.

\section{Discussion}

Endothelin-1 has become a major research topic since its discovery and characterisation as a potent vasoconstrictor. ${ }^{7}$ This potency has led to the idea that endothelin-1 might play a pathophysiological role in circulatory disorder resulting ischaemic or haemorrhagic changes in various organs. Whittle et al described an intraarterial injection of endothelin-1 that can dose dependently produce gastric mucosal lesions. ${ }^{*}$ Fewer studies have been carried out on microcirculatory hemodynamic changes of the stomach induced by endothelin, however. The present authors have recently shown that endothelin-1 induces the constriction of submucosal arterioles followed by the macromolecular permeable change in the mucosal 
microvasculature, and causes mucosal haemorrhagic changes in the rat stomach. ${ }^{9}$ In these changes, it is still unknown whether endothelin can directly cause the permeability change or indirectly induce the change after arteriolar constriction. Of interest, it was recently reported that endothelin- 1 and -3 can induce the release of tissue type plasminogen activator from endothelial cells. ${ }^{10}$ It is widely accepted that fibrin degradation products released after the action of plasmin on fibrin contribute to the development of inflammatory changes in several organs by increasing the permeability of the vasculature to protein." We previously showed that the excessive activation of tissue type plasminogen activator, mediated by microvascular endothelial cells, plays a crucial role in the development of gastric mucosal injury induced by ischaemia reperfusion in rats. ${ }^{1}$ The present study shows that the intraarterial injection of endothelin-1 increased tissue type plasminogen activator activity in the regional blood accompanying the mucosal injury in a time dependent manner. In addition, as shown in the Table and Figure 2, the regional tissue type plasminogen activator activity significantly increased before the development of mucosal damage and was proportional to the area of mucosal lesion at 30 minutes after the administration of endothelin-1. These results could suggest a prominent role of tissue type plasminogen activator in the pathogenesis of endothelin induced gastric mucosal damage.

Platelet activating factor is one of lipid mediators that is generated in a variety of cells upon chemical or immune stimulation. In addition to its biological activities in stimulating platelets and neutrophils, and enhancing vascular permeability, ${ }^{12}$ exogenous platelet activating factor has also been shown to be a potent ulcerogen, inducing extensive gastric mucosal damage and haemorrhage associated with septic shock. ${ }^{13}$ Sugatani et al recently determined the alteration of the platelet activating factor contents in rat gastric mucosa during water immersion stress and showed that endogenous platelet activating factor may actually be involved in the process of mucosal injury. ${ }^{6}$ The present study shows that endothelin-1 can increase the mucosal platelet activating factor content at five minutes after the administration in the rat stomach before the activation of regional tissue type plasminogen activator. We have shown also that CV-6209, a platelet activating factor blocker, eliminated the tissue type plasminogen activator activation and mucosal lesion induced by endothelin-1. Although the detailed mechanism is unknown, our data raise the possibility that endothelin-1 actually stimulates the production of platelet activating factor followed by the excessive release of tissue type plasminogen activator. These results are in accordance with the previous investigation that platelet activating factor activation directly increases the release of tissue type plasminogen activator from vessel walls in the experimental model of the isolated perfused rat hindlimb bed. ${ }^{14}$ Taken together with the present results, platelet activating factor is likely to modulate regional fibrinolytic activity during gastric mucosal injury induced by endothelin-1. This study was supported by a Grant-in-Aid for Scientific
Research from the Japanese Ministry of Education, Science and Culture of Japan and by a grant from Keio University, School of Medicine.

1 Kurose I, Suematsu M, Miura S, Suzuki M, Nagata $H$ Morishita $T$, et al. Involvement of superoxide anion and platelet-activating factor in increased tissue-type plasminoplatelet-activating factor in increased tissue-type plasminoThromb Res 1991; 62: 241-8.

2 Kurose I, Suematsu M, Miura S, Fukumura D, Serizawa $H$, Nagata $\mathrm{H}$, et al. In vivo mucosal and submucosal microvascular response in the rat stomach during autonomic nervous irritation. In: Yoshikawa $\mathrm{M}$, ed. New trends in autonomic nervons system research. Basic and clinical integration.Amsterdam:ElsevierSciencePublishersBV1991:179-83.

3 Korbut R, Lidbury P, Thomas GR, Vane JR. Fibrinolytic activity of endothelin-3. Thromb Res 1989; 55: 797-9.

4 Rånby $M$, Norrman $B$, Wallen P. A sensitive assay for tissue plasminogen activator. Thromb Res 1982; 27: 743-9.

5 Bligh EG, Dyer W. A rapid method of total lipid extraction and purification. Can $\mathcal{F}$ Biochem Physiol 1959; 37: 911-8.

6 Sugatani J, Fujimura K, Miwa M, Mizuno T, Sameshima Y, Saito K. Occurrence of platelet-activating factor (PAF) in normal rat stomach and alteration of PAF level by water immersion stress. FASEB f 1989; 3: 65-70.

7 Yanagisawa M, Kurihara H, Kimura S, Tomobe Y, Kobayashi $M$, Mitsui Y, et al. A novel potent vasoconstrictor peptide produced by vascular endothelial cells. Nature 1988; 332: 411-5.

8 Whittle BJR, Payne AN, Esplugues JV. Cardiopulmonary and ulcerogenic actions of endothelin-1 in the guinea pig and rat. F Cardiovasc Pharmacol 1989; 13 (suppl 5): S103-7.

9 Kurose I, Miura S, Fukumura D, Suematsu M, Nagata H, Tashiro H, et al. Role of endothelin in the pathogenesis of gastric mucosal hemorrhagic lesion. Fpn $\mathcal{f}$ Inflammation gastric mucosal

10 Pruis J, Emeis JJ. Endothelin-1 and -3 induce the release of tissue-type plasminogen activator and von Willebrand factor from endothelial cells. Eur f Pharmacol 1990; 187: 105-12.

11 Saldeen Y, Ryan JW, Berryer P. A peptide derived from fibrin(ogen) inhibits angiotensin converting enzyme and potenciates the effect of bradykinin. Thromb Res 1981; 23: 465-70.

12 Suematsu M, Kurose I, Asako H, Miura S, Tsuchiya M. In vivo visualization of oxyradical-dependent photoemmision during endothelium-granulocyte interaction in microvascular beds treated with platelet-activating factor. fBiochem 1989; 106: 355-60.

13 Rosam A-C, Wallace JL, Whittle BJR. Potent ulcerogenic actions of platelet-activating factor on the stomach. Nature 1986; 319: 54-6.

14 Emeis JJ, Kluft C. PAF-acether-induced release of tissue-type plasminogen activator from vessel walls. Blood 1985; 66: 86-91. 